\title{
Mechanisms of immune tolerance to allergens: role of IL-10 and Tregs
}

\author{
Cezmi A. Akdis ${ }^{1,2}$ and Mübeccel Akdis' \\ ${ }^{1}$ Swiss Institute of Allergy and Asthma Research (SIAF), University of Zurich, Davos, Switzerland. ${ }^{2}$ Christine Kühne - Center for Allergy Research and Education (CK-CARE), Davos, Switzerland.
}

\begin{abstract}
During the past 20 years, major advances have been made in understanding the molecular and cellular mechanisms of allergen tolerance in humans. The demonstration of $\mathrm{T}$ cell tolerance, particularly that mediated by the immunesuppressive functions of IL-10, led to a major conceptual change in this area. Currently, the known essential components of allergen tolerance include the induction of allergen-specific regulatory subsets of $T$ and $B$ cells, the immune-suppressive function of secreted factors, such as IL-10 and TCF- $\beta$, the production of IgG4 isotype allergen-specific blocking antibodies, and decreased allergic inflammatory responses by mast cells, basophils, and eosinophils in inflamed tissues.
\end{abstract}

\section{T cells and the allergic response}

Immune tolerance can develop against any immune-activating substance, and multiple mechanisms mediate this process. Deregulation of immune tolerance may lead to the development of allergies, asthma, tumors, chronic infections, rejection of transplanted organs, graft-versushost disease, and many autoimmune diseases. Allergic diseases are characterized by the induction of a type 2 immune response that includes Th2 cells and type 2 innate lymphoid cells (ILC2s), together with the production of allergen-specific IgE antibodies and increased eosinophil numbers in the affected tissues and sometimes in peripheral blood (1). Although there are many different ways to treat allergic disease-associated symptoms, currently, the only long-term curative treatment is allergen-specific immunotherapy (AIT), which involves the administration of increasing doses of the causative allergen. Over time, AIT induces a state of allergen-specific immune tolerance. AIT has been performed for more than 100 years, though it has only been within the past two decades that the mechanisms that mediate the action of AIT have been slowly uncovered (2). After the discovery of Th1 and Th2 cells in 1986 (3), it was suggested that a Th2 response underlies the development of allergic diseases and that Th1 responses are predominant in infections and autoimmunity. Following these initial findings, the general dogma was that a switch toward a Th1 response would be required for the successful treatment of allergies by AIT, and a switch toward a Th2 response would be beneficial for the treatment of autoimmunity.

In the mid-1990s, our group was working on the mechanisms of action of AIT in conventional and $\mathrm{T}$ cell epitope peptide immunotherapies $(4,5)$. We were using honey bee venom allergy and its major allergen phospholipase $\mathrm{A}_{2}$ as a model to investigate antigen/allergen-specific immune response development in humans (4). In a 1996 article published in the JCI, we demonstrated that allergen-specific $\mathrm{T}$ cell tolerance was induced during the course of AIT (4). Two months after the beginning of venom immunotherapy, the proliferation of $\mathrm{T}$ cells specifically targeting phospholipase $\mathrm{A}_{2}$ and its $\mathrm{T}$ cell epitope peptides as well as the secretion of both Th2 (IL-4, IL-5, and IL-13) and Th1 (IL-2 and IFN- $\gamma$ ) cytokines were abolished.
These data directly challenged the dogma that switching the balance between Th1 and Th2 responses is playing a role in treatment and suggested that the development of full $\mathrm{T}$ cell tolerance and suppression of both Th1 and Th2 subsets are taking place. As a control antigen, we demonstrated that tetanus toxoid-induced $\mathrm{T}$ cell proliferation and cytokine production remained unchanged following venom-specific AIT, demonstrating that the immune tolerance was specific to venom antigens and did not extend to other antigens. In addition, the state of $\mathrm{T}$ cell tolerance induced by AIT was altered in vitro by treatment with IL-2, IL-4, and IL-15. This was one of the first demonstrations that antigen-specific effector $\mathrm{T}$ cells have plasticity, suggesting that microenvironmental cytokines are important for determining success or failure in AIT (4). During these experiments, we were fortunate to be working with highly pure synthetic peptides and purified bee venom antigens collected in a sterile way. This enabled us to demonstrate immune tolerance, because any lipopolysaccharide contamination during collection and extraction of environmental allergens, such as house dust mites and pollens, would have led to results showing a skew from Th2 toward Th1.

\section{IL-10-producing Tregs in immune tolerance}

In hindsight, our research continued to elucidate the molecular and cellular mechanisms of $\mathrm{T}$ cell tolerance to allergens, and in our 1998 study published in the JCI, we demonstrated that human IL-10-producing Tregs ( $\operatorname{Tr} 1$ cells) are linked to an antigen-specific suppressor function (Figure 1 and ref. 6). Intracytoplasmic cytokine staining of circulating lymphocytes revealed that IL-10 was initially produced by $\mathrm{CD} 4{ }^{+} \mathrm{CD} 25^{+}$ allergen-specific $\operatorname{Tr} 1$ cells and then by $\mathrm{B}$ cells and monocytes. These IL-10-secreting $\operatorname{Tr} 1$ cells were substantially increased as early as seven days after the start of bee venom AIT in allergic individuals. Fol- 


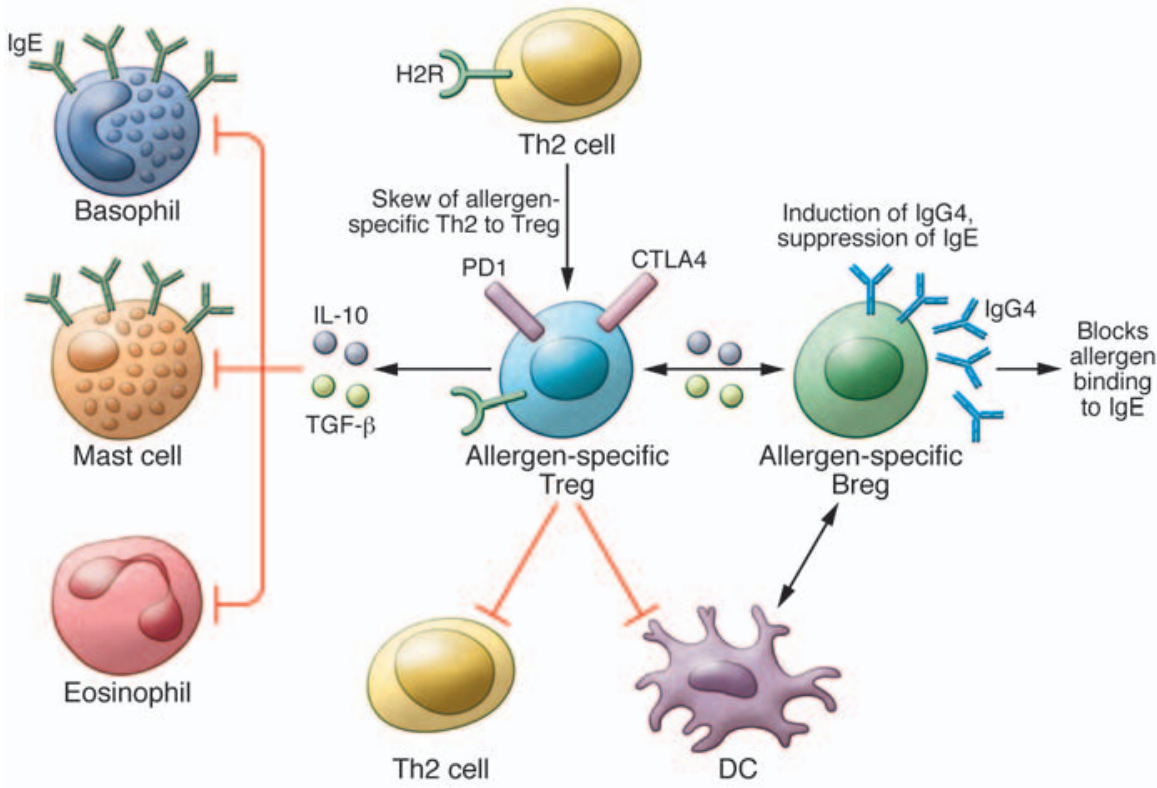

Figure 1. Mechanisms of allergen tolerance. The induction of allergen-specific Tregs, which switch from allergen-specific Th2 cells is one of the initial events in the development of allergen tolerance. The effector cells of allergic inflammation - mast cells, basophils, and eosinophils - are regulated by suppressive and regulatory functions of Tregs in several ways. Treg-secreted IL-10 and TGF- $\beta$ suppress these cells. Tregs also suppress Th2 cells and their cytokines, preventing the provision of survival factors for these allergy effector cells. IL-10 and TCF- $\beta$ suppress IgE production by B cells, and meanwhile, IL-10 induces IgG4. IL-10-producing regulatory B cells (Bregs) play a role in suppression of allergen-specific T cells and mainly switch to IgC4-producing plasma cells. H2R plays a role in the suppression of Th2 cells, inflammatory dendritic cells, and basophils.

lowing these initial findings, one major question was whether these Tr1 cells also develop during other types of AIT against different allergens. It took many years to demonstrate that $\operatorname{Tr} 1$ cells are generated in response to other immunotherapies such as sublingual immunotherapy, other allergens such as grass pollen and house dust mites, and peptide immunotherapies in allergy and autoimmune diseases (7-12). In addition, $\operatorname{Tr} 1$ cells were demonstrated to be present in high-dose exposure to allergen models, such as nonallergic beekeepers and cat owners $(6,13,14)$.

\section{Tr1 cells and recently discovered} Br1 cells support a healthy immune response to allergens

Studies during the past two decades have demonstrated that there are two broad subsets of $\mathrm{CD}^{+} \mathrm{CD}^{+}$Tregs. One subset is the naturally occurring thymus-derived $\mathrm{CD}^{+} \mathrm{CD} 25^{+} \mathrm{FOXP}^{+}{ }^{+}$Tregs, also called natural Tregs (nTregs), and the other subset is the inducible Tregs (iTregs). Three main subsets of iTregs have been characterized: FOXP3-expressing iTregs, CD4 ${ }^{+} \mathrm{FOXP}^{-}$ IL-10-producing Tr1 cells, and TGF- $\beta$ - expressing Th3 cells. It has been repeatedly shown that all three subsets of iTregs coexist and overlap in many immune tolerance-related situations in humans. For example, antigen-specific $\mathrm{CD} 4^{+} \mathrm{T}$ cells that express IL-10, TGF- $\beta$, and FOXP3, or some combination of these markers, increase in nasal biopsies $(12,15-17)$ and peripheral blood (7-9) in response to AIT at the healing phase.

Tr1 cells have been shown to be important for the maintenance of a healthy immune response in different diseases, such as allergy, many autoimmune conditions, transplantation tolerance, and graft-versushost disease in both humans and mice (13, $18-26)$. Although IL-10 is the main cytokine produced by $\operatorname{Tr} 1$ cells, these cells also produce TGF- $\beta$ and low-to-medium levels of IFN- $\gamma$ and IL-5, but not IL-4 or IL-2 (27, 28). It took almost a decade to demonstrate that human $\operatorname{Tr} 1$ cells suppress effector $\mathrm{T}$ cell responses by multiple mechanisms that depend on IL-10, TGF- $\beta$ (7), PD-1, CTLA-4 (29), and histamine receptor 2 (H2R) (13).

IL-10 has a potent immunosuppressive capacity that is crucial not only for the establishment of peripheral tolerance to allergens, but also in protecting the host from exaggerated inflammatory responses to pathogens as well as to autoimmune diseases (30). IL-10 directly inhibits $\mathrm{T}$ cells through suppression of CD28-and ICOS-dependent T cell costimulation (31). In addition, IL-10 inhibits the production of proinflammatory cytokines, chemokines, and chemokine receptors as well as the expression of MHC class II and costimulatory molecules CD80/CD86 on monocytes/macrophages and dendritic cells (30).

In addition to $\mathrm{T}$ cell regulation, IL-10 secreted from $\operatorname{Tr} 1$ cells plays a major role in the induction of IgG4 and suppression of $\operatorname{IgE}(6,32)$. Moreover, it was recently demonstrated that IL-10-secreting B regulatory (Br1) cells essentially contribute to allergen tolerance (ref. 33 and Figure 1). Phospholipase A2-specific Br1 cells from nonallergic beekeepers and those that are induced after AIT showed increased expression of IL-10 with an antigen-specific suppressor capacity. A major finding of this study was that IgG4 production is specifically confined to Br1 cells. IgG4 represents a noninflammatory Ig isotype that does not activate complement and plays an IgE-blocking antibody role for the degranulation of mast cells and basophils (33).

\section{Conclusions}

Specific $\operatorname{Tr} 1$ cells and immune tolerance development are essential for the induction and maintenance of healthy immune responses to allergens. The relationship between clinical allergen tolerance and immune tolerance has been observed by direct analysis of the affected tissues and skin during late-phase responses in humans who have undergone AIT with whole allergen and $\mathrm{T}$ cell epitope peptides as well as in individuals who have been exposed to naturally high doses of allergens. As of today, the concept that Tr1 cells mediate antigen-specific $\mathrm{T}$ cell tolerance has been demonstrated and generally accepted after the publication of several thousand studies on immune regulation.

\section{Acknowledgments}

The authors' laboratories are supported by grants from the Swiss National Foundation (320030_140772 and 310030_156823) and CK-CARE and from the European 7th Framework projects Mechanisms of 
the Development of Allergy (MeDALL) (261357) and Post-Infectious Immune Reprogramming and Its Association with Persistence and Chronicity of Respiratory Allergic Diseases (PREDICTA) (260895).

Address correspondence to: Cezmi A. Akdis, Swiss Institute of Allergy and Asthma Research (SIAF), Obere Str. 22 CH-7270, Davos Platz, Switzerland. Phone: 41.81.410.08.48; E-mail: akdisac@ siaf.uzh.ch.

1. Akdis CA. Therapies for allergic inflammation: refining strategies to induce tolerance. $\mathrm{Nat} \mathrm{Med}$. 2012;18(5):736-749.

2. Burks AW, et al. Update on allergy immunotherapy: American Academy of Allergy, Asthma \& Immunology/European Academy of Allergy and Clinical Immunology/PRACTALL consensus report. J Allergy Clin Immunol. 2013;131(5):1288-1296.e3.

3. Mosmann TR, Cherwinski H, Bond MW, Giedlin MA, Coffman RL. Two types of murine helper T cell clones. 1. Definition according to profiles of lymphokine activities and secreted proteins. JImmunol. 1986;136(7):2348-2357.

4. Akdis CA, et al. Epitope-specific T cell tolerance to phospholipase A2 in bee venom immunotherapy and recovery by IL-2 and IL-15 in vitro. J Clin Invest. 1996;98(7):1676-1683.

5. Müller U, et al. Successful immunotherapy with T-cell epitope peptides of bee venom phospholipase A2 induces specific T-cell anergy in patients allergic to bee venom. JAllergy Clin Immunol. 1998;101(6 pt 1):747-754.

6. Akdis CA, Blesken T, Akdis M, Wüthrich B, Blaser K. Role of interleukin 10 in specific immunotherapy. JClin Invest. 1998;102(1):98-106.

7. Jutel M, et al. IL-10 and TGF- $\beta$ cooperate in the regulatory $\mathrm{T}$ cell response to mucosal allergens in normal immunity and specific immunotherapy. Eur JImmunol. 2003;33(5):1205-1214.

8. Francis JN, Till SJ, Durham SR. Induction of $\mathrm{IL}-1 \mathrm{O}^{+} \mathrm{CD} 4^{+} \mathrm{CD} 25^{+} \mathrm{T}$ cells by grass pollen immunotherapy. JAllergy Clin Immunol. 2003;111(6):1255-1261.

9. Ling EM, et al. Relation of $\mathrm{CD} 4^{+} \mathrm{CD} 25^{+}$ regulatory T-cell suppression of allergendriven T-cell activation to atopic status and expression of allergic disease. Lancet. 2004;363(9409):608-615.

10. Bohle B, Kinaciyan T, Gerstmayr M, Radakovics A, Jahn-Schmid B, Ebner C. Sublingual immunotherapy induces IL-10-producing $\mathrm{T}$ regulatory cells, allergen-specific T-cell tolerance, and immune deviation. JAllergy Clin Immunol. 2007;120(3):707-713.

11. Larche M, Wraith DC. Peptide-based therapeutic vaccines for allergic and autoimmune diseases. Nat Med. 2005;11(4 suppl):S69-S76.

12. Robinson DS, Larche M, Durham SR. Tregs and allergic disease. J Clin Invest. 2004;114(10):1389-1397.

13. Meiler F, Zumkehr J, Klunker S, Ruckert B, Akdis CA, Akdis M. In vivo switch to IL-10-secreting T regulatory cells in high dose allergen exposure. JExp Med. 2008;205(12):2887-2898.

14. Reefer AJ, et al. A role for IL-10-mediated HLA-DR7-restricted T cell-dependent events in development of the modified $\mathrm{Th} 2$ response to cat allergen. JImmunol. 2004;172(5):2763-2772.

15. Radulovic S, Jacobson MR, Durham SR, Nouri-Aria KT. Grass pollen immunotherapy induces Foxp3-expressing $\mathrm{CD} 4{ }^{+} \mathrm{CD} 25^{+}$cells in the nasal mucosa. J Allergy Clin Immunol. 2008;121(6):1467-1472.e1.

16. Nouri-Aria KT, et al. Grass pollen immunotherapy induces mucosal and peripheral IL-10 responses and blocking IgG activity. J Immunol. 2004;172(5):3252-3259.

17. Pilette C, et al. Grass pollen immunotherapy induces an allergen-specific IgA2 antibody response associated with mucosal TGF- $\beta$ expression. J Immunol. 2007;178(7):4658-4666.

18. Gagliani N, et al. Coexpression of CD $49 \mathrm{~b}$ and LAG-3 identifies human and mouse $\mathrm{T}$ regulatory type 1 cells. Nat Med. 2013;19(6):739-746.

19. Guichelaar T, et al. Autoantigen-specific IL-10-transduced T cells suppress chronic arthritis by promoting the endogenous regulatory IL-10 response. JImmunol. 2008;180(3):1373-1381.

20. Zohar Y, et al. CXCL11-dependent induction of FOXP3-negative regulatory $\mathrm{T}$ cells suppresses autoimmune encephalomyelitis. J Clin Invest. 2014;124(5):2009-2022.

21. Stewart CA, et al. Interferon-dependent IL-10 production by Tregs limits tumor Th17 inflam- mation. J Clin Invest. 2013;123(11):4859-4874.

22. Gupta S, et al. Allograft rejection is restrained by short-lived TIM- $3^{+} \mathrm{PD}-1^{+}{ }^{+}{ }{ }^{2} 3^{+}{ }^{+}$Tregs. JClin Invest. 2012;122(7):2395-2404.

23. Campbell JD, et al. Peptide immunotherapy in allergic asthma generates IL-10-dependent immunological tolerance associated with linked epitope suppression. J Exp Med. 2009;206(7):1535-1547.

24. Huang H, Ma Y, Dawicki W, Zhang X, Gordon $J R$. Comparison of induced versus natural regulatory T cells of the same TCR specificity for induction of tolerance to an environmental antigen. J Immunol. 2013;191(3):1136-1143.

25. Soroosh P, et al. Lung-resident tissue macrophages generate Foxp $3^{+}$regulatory $\mathrm{T}$ cells and promote airway tolerance. J Exp Med. 2013;210(4):775-788.

26. Lloyd CM, Hawrylowicz CM. Regulatory T cells in asthma. Immunity. 2009;31(3):438-449.

27. Bacchetta R, Sartirana C, Levings MK, Bordignon C, Narula S, Roncarolo MG. Growth and expansion of human $\mathrm{T}$ regulatory type 1 cells are independent from TCR activation but require exogenous cytokines. Eur JImmunol. 2002;32(8):2237-2245.

28. Allan SE, et al. CD4 ${ }^{+} \mathrm{T}$-regulatory cells: toward therapy for human diseases. Immunol Rev. 2008;223:391-421.

29. Akdis M, et al. Immune responses in healthy and allergic individuals are characterized by a fine balance between allergen-specific $\mathrm{T}$ regulatory 1 and T helper 2 cells. J Exp Med. 2004;199(11):1567-1575.

30. O'Garra A, Vieira PL, Vieira P, Goldfeld AE. IL-10-producing and naturally occurring $\mathrm{CD}^{+}{ }^{+}$ Tregs: limiting collateral damage. JClin Invest. 2004;1114(10):1372-1378

31. Taylor A, et al. IL-10 inhibits CD28 and ICOS costimulations of $\mathrm{T}$ cells via src homology 2 domain-containing protein tyrosine phosphatase 1. JAllergy Clin Immunol. 2007;120(1):76-83.

32. Meiler F, Klunker S, Zimmermann M, Akdis CA Akdis M. Distinct regulation of IgE, IgG4 and IgA by $\mathrm{T}$ regulatory cells and toll-like receptors. Allergy. 2008;63(11):1455-1463.

33. van de Veen $\mathrm{W}$, et al. IgG4 production is confined to human IL-10-producing regulatory B cells that suppress antigen-specific immune responses. JAllergy Clin Immunol. 2013;131(4):1204-1212. 